\title{
A Internet e Seus Espaços de Autoria: a escrita online em fóruns, wikis e blogs
}

\section{The web and its authorship spaces: the online writing on forums, wikis and blogs}

\begin{abstract}
Resumo: Este trabalho apresenta uma análise de espaços de autoria em um ambiente virtual de aprendizagem, buscando compreender as relações que os sujeitos constroem entre si e com o próprio ambiente por meio da escrita online. São caracterizados três espaços de escrita online - fóruns, wikis e blogs - trazendo dados coletados por meio da observação virtual e analisados a partir dos pressupostos da filosofia da linguagem. Ao buscar-se compreender por que o texto é escrito, para quem é escrito, como é escrito e o que mais se puder perceber a partir dessa escrita, reconhece-se o processo educativo nesse ambiente como linguisticamente e socialmente constituído. Os resultados apontaram para o papel determinante da autoria em ambientes virtuais de aprendizagem, possibilitando ao sujeito uma atitude responsiva ativa e não somente de leitor de materiais postados por uma equipe de tutoria.
\end{abstract}

Palavras-chave: Autoria. Ambientes virtuais de aprendizagem.

Abstract: This paper presents an analysis of spaces of authorship in a virtual learning environment, seeking to understand the relationships that individuals construct each other and with the environment itself by online writing. Three online writing spaces are characterized - forums, wikis and blogs - bringing data collected through virtual observation and analyzed from the assumptions of the philosophy of language. In seeking to understand why the text is written, to whom it is written, how it is written and what more if you can see from this writing, it recognizes the educational process in this environment as linguistically and socially constituted. The results pointed to the role of authorship in virtual learning environments, enabling the subject to an active and responsive attitude and not only reader of materials posted by a mentoring team.

Keywords: Authorship. Virtual learning environment.

MEDEIROS, Zulmira; NASCIMENTO, Silvania Sousa. A Internet e Seus Espaços de Autoria: a escrita online em fóruns, wikis e blogs. Informática na Educação: teoria e prática, Porto Alegre, v. 18, n. 1, p. 97-113, jan./jun. 2015.
Zulmira Medeiros

\author{
Silvania Sousa Nascimento \\ Universidade Federal de Minas Gerais
}

\section{Introdução}

$\mathbf{P}$ artindo de uma discussão em torno do contexto da educação a distância e do conceito de autoria, este estudo analisa um ambiente virtual de aprendizagem, buscando compreender as relações que os sujeitos constroem entre si e com o próprio ambiente por meio da escrita online. Tal estudo insere-se em uma pesquisa de doutoramento já concluída, na qual se investigou também os processos de letramento digital e de apropriação de novos gêneros textuais e discursivos vivenciados por alunos de um curso de graduação a distância (MEDEIROS, 2011).

O estudo empírico deu-se entre os alunos da primeira oferta (2008-2011) do curso de graduação em Pedagogia, realizado na modalidade a distância, pela Universidade Aberta 
do Brasil (UAB) e pela Universidade Federal de Minas Gerais (UFMG), funcionando, então, em nove polos localizados em diferentes municípios do interior do Estado de Minas Gerais. Em cada polo foram constituídas duas turmas de 25 alunos em cada, totalizando cerca de 450 alunos, sujeitos desta pesquisa. Como ambiente virtual da aprendizagem foi utilizada a plataforma MOODLE, onde pode ser mantido um contato via internet entre coordenação, tutores e alunos, por meio de chats, fóruns, envio de mensagens e publicação de conteúdos, assim como postagem, pelos alunos, das atividades solicitadas.

Neste texto, são caracterizados três espaços de escrita online - fóruns, wikis e blogs - trazendo dados coletados por meio da observação virtual e analisados a partir dos pressupostos da filosofia da linguagem.

\section{A Educação a Distância e a Web 2.0}

Fazer um curso superior na modalidade a distância pode ser, para muitos sujeitos, o único caminho possível para se graduar, a única maneira de chegar à universidade, ou de a universidade chegar até eles. Superando o aspecto limitador dessa realidade e pensando no uso de recursos tecnológicos tão presentes nos cursos a distância, podemos considerar que tal fato acaba por colocar ao alcance desses alunos possibilidades por vezes não vivenciadas pelos alunos dos cursos de graduação presenciais.

Quando eu pensei que não havia possibilidade de fazer uma graduação tão cedo na minha vida. Lá estava a luz no fim do túnel, UAB-UFMG. Agarrei a essa oportunidade com unhas e dentes. Como tudo na minha vida, a UFMG tem sido mais um desafio, ou me-
Ihor, uma série de desafios. A começar pela experiência do vestibular em 2007, que foi o primeiro que fiz na vida, depois responder ao questionário sócio econômico e conseguir me isentar da taxa de CFB que faríamos a cada seis meses, tive que comprar um computador em 18 parcelas, ainda faltam 3 para terminar, a informática é um constante aprendizado pois mal sabia digitar e, nossa sala de aula é o bendito computador. Cada guia de estudos que se abre é uma caixa de surpresas, agradáveis é claro, cada encontro presencial é um frio na barriga como se fosse a primeira vez (Excerto do blog da aluna Carolina, 20/10/2009).

Nesse sentido, a educação a distância cumpre um papel democratizador e socializador, ao demandar, viabilizar, oportunizar o contato e o uso das tecnologias digitais, promovendo uma formação diferenciada ao preparar o indivíduo para viver em uma sociedade tecnológica, ao preparar melhor o docente ${ }^{1}$ para uma geração de alunos que lida com recursos tecnológicos em seu dia-a-dia. E até mesmo ao preparar melhor o professor que pode, em sua trajetória profissional, se deparar com a docência na educação a distância como uma possibilidade de atuação. Além disso, é necessário considerar vivências em diferentes situações de uso das tecnologias digitais, buscando a preparação tecnológica do indivíduo para além do papel de mero utilizador, proporcionando recursos e atividades que favoreçam a criação, dando aos participantes a possibilidade de exercerem a autoria, de se expressarem.

A própria internet, ao longo dos anos, tem se mostrado como um espaço mais aberto à participação do usuário, antes visto como um leitor, um consumidor de informações. Essa diferença na forma como o usuário passa a ser

${ }^{1}$ Neste caso específico, em que estamos tratando de um curso de Pedagogia. 
tratado é marcada pela criação do termo web 2.0, com a disponibilização e uso de aplicativos online que favorecem o exercício da autoria. Essa inclusão do usuário comum, que não possui conhecimentos técnicos de programação de softwares, torna-se possível por meio de interfaces acessíveis, permitindo a qualquer pessoa que saiba usar recursos mínimos de informática, participar produzindo, comentando ou organizando conteúdos na web. Atualmente já se fala em web 3.0 e web 4.0, conforme sistematiza a Figura 1:

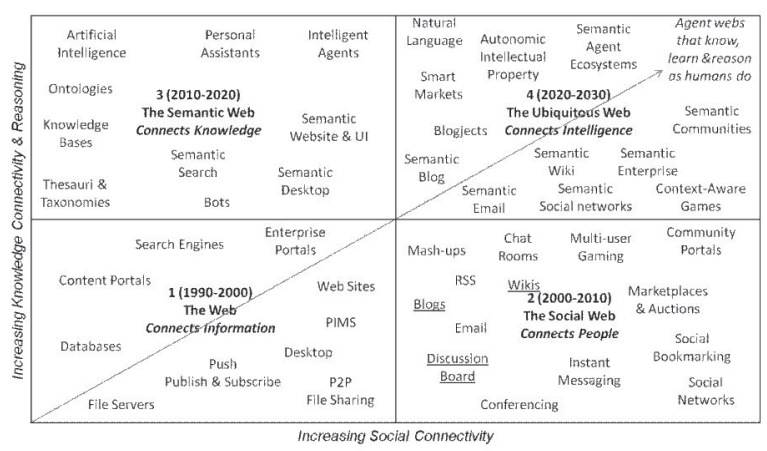

FIGURA 1 - Recursos Característicos de Cada Fase da $W e b^{2}$. FONTE: Klis (2008).

É interessante considerarmos que diferenças entre cada uma das fases da web não significam ou não se deram apenas a partir de mudanças nas tecnologias empregadas, mas principalmente pela natural evolução no perfil dos seus usuários e dos desenvolvedores de softwares.

Embora já tenhamos o anúncio das fases 3.0 e 4.0 (sobre as quais não nos deteremos em caracterizar) e alguns dos recursos descri-

\footnotetext{
2 Esta figura é uma adaptação de uma imagem publicada no blog <http://www.henkjanvanderklis.nl/weblog/labels/ web\%204.0.html>, cujo autor faz referência a Nova Spivack, fundador da empresa americana Radar Networks. Várias imagens similares podem ser localizadas na $w e b$, sendo que a maior parte delas possuem como referência o mesmo Nova Spivack e seus artigos publicados na rede.
}

tos na fase 2.0 já estivessem presentes anteriormente de forma mais discreta, foi a web 2.0 que rompeu a fronteira para relações mais colaborativas entre os usuários e destes com os conteúdos da rede. Para esta pesquisa, interessa justamente essa transição, de um usuário, antes consumidor de informações, que passa a ter ao seu alcance espaços em que pode também se expressar por meio da escrita, publicando-a e compartilhando-a com os demais usuários. O uso da internet e dos ambientes virtuais de aprendizagem podem favorecer esse exercício da autoria, conforme buscamos apresentar no próximo tópico.

\section{O Exercício da Autoria na Escrita Online}

O termo autoria pode remeter a diferentes significados e, ainda que o delimitemos aos ambientes virtuais de aprendizagem, percebemos que é empregado com finalidades distintas.

No campo da Ciência da Computação, Amorim (2005, p. 25) define autoria como o "[...] termo utilizado para criação de páginas para internet, multimídia interativa e qualquer forma de aprendizagem mediada por computador". Nessa e em outras pesquisas (BEICHNER, 1994, LIMA, M.D.A., 2002, SAADE, 2003) encontramos estudos sobre sistemas computacionais que viabilizam o exercício da autoria sem exigir o uso de linguagens ou códigos de programação computacional. Se nas décadas anteriores era comum o desenvolvimento de softwares de autoria a serem instalados e usados localmente no computador, nos últimos anos, a Ciência da Computação tem se dedicado ao estudo e ao desenvolvimento de plataformas e softwares que viabilizem a autoria na web. 
Tais ferramentas de autoria podem possibilitar desde atividades mais simples, como a elaboração de textos ou documentos hipermídia, até cursos completos, sem que o autor necessite de conhecimentos em computação (LIMA, M.D.A., 2002). Assim, as ferramentas de autoria favorecem a produtividade e aprendizagem simultâneas, pela facilidade com que o usuário elabora e materializa a sua criação (AMORIM, 2005). De acordo com Saade (2003), nas ferramentas de autoria, o poder de expressão é proporcional à complexidade do modelo hipermídia. Ou seja, um modelo simples possibilita um pequeno poder de expressão, ao passo que se o usuário deseja maiores possibilidades de expressão, a complexidade de uso também cresce.

Neste trabalho, não nos deteremos às especificidades técnicas mais internas (relativas à modelagem computacional) das ferramentas de autoria, apenas àquelas que afetam mais diretamente o seu uso pelos nossos sujeitos, como as relacionadas ao leiaute e à navegação. Tampouco investigaremos ferramentas de autoria para construção de cursos hipermidiáticos ou materiais afins. Interessa-nos espaços para autoria de textos simples, tais como fóruns, wikis e blogs. Observe o leitor que não é tanto a ferramenta computacional de autoria que atrai o nosso olhar, mas a função de autoria, a ação de criação e postagem de textos em espaços interativos na web. Entretanto, mesmo que nos distanciemos um pouco do foco que a Ciência da Computação dá ao conceito, consideramos importante trazer aqui esse viés, no intuito de localizá-lo em nossa investigação, que contempla espaços em que se verifica "[...] a transformação de uma barreira básica de construção e produção [...] na web: o conhecimento da linguagem HTML" (PRIMO; RECUERO, 2003, p. 62). Para os autores, nesses espaços "[...] essa barreira é superada, transformando qualquer internauta em um potencial autor na web" (PRIMO; RECUERO, 2003, p. 62).

Já no campo da Linguística, a autoria vem sendo amplamente estudada (FRANCELINO, 2007, BEZERRA, 2008, LIMA, C.S., 2008), predominantemente nas matrizes conceituais da análise do discurso, examinado-se questões inerentes às subjetividades e identidades na constituição do sujeito-autor em sua relação com o outro e com o meio. Francelino (2007) investiga situações de aula, no intuito de observar a constituição do discurso do professor, a partir do uso que faz do discurso de outrem, enquanto Bezerra (2008) se propõe analisar os estilos em textos produzidos pelas crianças no âmbito escolar. Notamos que para muitos desses pesquisadores, a autoria é algo caracteristicamente coletivo, socialmente constituído, sobretudo para aqueles que trazem autores como Bakhtin entre seus referenciais teóricos. O foco que tais pesquisas dão ao conceito de autoria aproxima-se um tanto mais do que aqui nos propomos discutir.

Mas é num campo de interseção da Ciência da Computação e da Linguística e destas com a Educação que encontramos o conceito de autoria (AXT, 1998, AXT; ELIAS, 2003, AXT et al., 2006, FREITAS; COSTA, 2005, FREITAS; PEREIRA, 2009) que mais se aproxima do nosso objeto de pesquisa, justamente por examinarmos os espaços de escrita e de expressão do sujeito em um ambiente virtual de aprendizagem, buscando compreender a sua relação com os demais sujeitos nesse ambiente e com o próprio ambiente. Freitas e Pereira (2009) discutem o exercício da autoria em blogs literários no contexto das aulas de Língua Portuguesa no Ensino Fundamental, como espaço de formação do leitor/autor. Freitas e Costa 
(2005) tratam da produção escrita de adolescentes, suas novas maneiras de ler e de escrever na web, trazendo para análise a autoria em espaços virtuais diversos, como salas de bate-papo e listas de discussão. Também Axt, em seus diversos trabalhos, aborda o exercício da autoria na perspectiva da possibilidade de expressão e de produção de sentidos, de aprendizagem como processo individual e coletivo (AXT et al., 2006).

De certo modo, o conceito de autoria veio passando, ao longo dos séculos, por desconstruções e reconstruções. Chartier (1999) nos fala das diferentes revoluções vividas pelos processos de escrita e de leitura. Do manuscrito para o texto tipográfico houve uma mudança nas formas de produção e de reprodução do texto, mas o suporte permaneceu - o códex. Já com o texto eletrônico, houve uma ruptura, tanto quanto ao suporte material, quanto às maneiras de ler (agora na tela), alterando-se, inclusive, as relações corporais entre o autor ou o leitor e o livro. Mudam também os papéis: autor, editor, distribuidor agora podem ser a mesma pessoa; o papel do crítico é ampliado a todo leitor, pois as redes eletrônicas favorecem as intervenções no espaço de discussão ali constituído. Isso significa que, no texto eletrônico, a participação do leitor vai além da sua interpretação, da atribuição de sentido, pois pode interferir na própria escrita. Nos contextos de autoria a que nos referimos neste estudo, o internauta, antes apenas um leitor, é agora convidado a expressar-se, a também produzir e dar identidade ao texto.

É essa noção de protagonismo que nos instiga à investigação acerca dos espaços de autoria nos ambientes virtuais de aprendizagem, já que permitem aos sujeitos superarem a condição de meros consumidores de informação para também produzirem, se expressarem e postarem no espaço interativo a sua produção. Embora saibamos que, mesmo enquanto leitor, o sujeito não é passivo, entendemos que a possibilidade de publicar a sua escrita no ambiente virtual promove modificações no papel que ele desempenha diante das tecnologias digitais e dos seus próprios textos. Se antes o exercício da escrita era algo restrito a alguns privilegiados e apenas o acesso à leitura era (e ainda é) mais compartilhado, a tela vem modificando esse cenário. Basta voltarmos o nosso olhar para um ambiente virtual de aprendizagem que exige a escrita na tela, que se propõe ser um espaço onde o sujeito pode entrar, escrever, se comunicar e se expressar por meio da sua escrita.

Compreendendo a expressão como o processo de exteriorização pelo sujeito, por meio de um código ou signo, de algo que tenha sido formado em seu interior e, sendo esse processo determinado pelas condições reais de produção da enunciação, temos o contexto externo como definidor dessa expressão (BAKHTIN, 2006). Esta, por sua vez materializada, passa a estruturar a atividade mental e aí então veremos que é "[...] o nosso mundo interior que se adapta às possibilidades de nossa expressão, aos seus caminhos e orientações possíveis" (BAKHTIN, 2006, p. 122). Para esse autor, o próprio sujeito se constitui no reconhecimento do outro, a sua fala é determinada pela presença do outro, pois o sujeito fala para o outro, pelo outro, com o outro. Nesse sentido, acreditamos ser coerente trabalhar com um conceito de autoria mais próximo da coletividade do que da individualidade, ou seja, admitindo que o texto não pertence apenas a quem o produziu, mas também aos interlocutores e ao meio em que foi produzido, dado o caráter social que the é constitutivo. O sujeito leitor/escritor, ouvinte/falante, interlocutor, enfim, usa a sua voz, a 
sua escrita e também se presta a ouvir a voz do outro, a ler o texto do outro, instaurando-se aí uma autoria coletiva pautada na interlocução, na interação dialógica (AXT, 2004, 2006).

\section{Referencial Metodológico}

Buscando compreender as relações que os sujeitos pudessem estabelecer entre si e com o ambiente virtual de aprendizagem por meio da sua escrita nesse ambiente, deparamo-nos com a concepção de linguagem como um fenômeno histórico e socialmente constituído, fortemente ancorada na realidade imediata e no contexto mais amplo. Nesse sentido, encontramos na obra de Mikhail Bakhtin $(1997,2006)$ orientações condizentes com nossos objetivos e que passaram a referenciar o nosso quadro metodológico. Bakhtin caracteriza a linguagem como um processo constante de interação, possível a partir do diálogo nas situações de comunicação. Neste estudo, reconhecemos que um ambiente virtual de aprendizagem pode proporcionar um espaço de diálogo, de interação entre os participantes, ao possibilitar a sua expressão por meio do exercício da autoria, ou seja, da publicação de conteúdos em forma de textos, mensagens e/ou comentários.

Para operacionalizar nossa investigação em busca das respostas aos nossos questionamentos, fizemos uso de alguns elementos da análise da conversação (MARCUSCHI, 2006, KERBRAT-ORECCHIONI, 2006) e da análise do conteúdo (BARDIN, 1977). Principalmente no trabalho de descrição dos dados, tais métodos mostraram-se convenientes devido às suas características estruturais e organizacionais.

$\mathrm{Na}$ análise conversacional, partimos do princípio de que a interação face a face não é condição indispensável, mas sim a interação centrada (algo sobre o que conversar), a existência de pelo menos dois interlocutores, de pelo menos uma troca de turno, de uma identidade temporal, o mesmo direito de falar e um contexto em que os participantes estivessem engajados (MARCUSCHI, 2006). Utilizamos essa abordagem de análise das práticas discursivas presentes nos fóruns online, primeiramente por atenderem aos princípios listados acima, mas, principalmente, por tal análise nos possibilitar compreender a organização das interações. O tratamento de alguns elementos organizacionais, como a troca de turnos e as sequências, foi específico a este contexto. Esclarecemos, assim, que não se trata, nesta pesquisa, de uma análise conversacional stricto sensu, dadas as particularidades da conversa em um fórum online, mas da utilização de algumas diretrizes do método que se mostraram convenientes ao nosso contexto de estudo.

Por meio da análise de conteúdo (BARDIN, 1977), investigamos, nos textos produzidos e publicados no ambiente virtual, os indicadores e referências que pudessem nos trazer elementos relacionados às questões levantadas neste estudo. Pretendemos com essa abordagem extrapolar os aspectos quantitativos e chegarmos a um patamar de análise qualitativa das práticas discursivas manifestadas nos textos dos fóruns, blogs e wikis, buscando compreender as relações que os sujeitos construíram entre si e com o ambiente virtual por meio das interações.

A partir dessa proposta metodológica, procuramos analisar os processos interativos dos sujeitos entre si e destes com o ambiente virtual de aprendizagem. Sabemos que ambas as abordagens aqui propostas possuem características estruturais e organizacionais específi- 
cos, mas tais regras foram vistas como procedimentos analíticos, e não como padrões de funcionamento de um fenômeno (a linguagem) que sabemos ser dinâmico.

Assim como Bakhtin (2006), ressaltamos a natureza social e histórica dessa produção de enunciados a que nos propusemos investigar. Consideramos que compreendendo as sequências nas interações nos fóruns e os textos publicados nos blogs e wikis como enunciados produzidos por sujeitos engajados em um contexto específico, um ambiente virtual de aprendizagem, podemos melhor interpretar os processos de aprendizagem nas relações ali estabelecidas por meio da escrita.

Em relação aos instrumentos de pesquisa, realizamos a busca pelas informações por meio de questionários online e observações virtuais. A análise da prática discursiva deu-se a partir dos textos construídos e publicados pelos sujeitos nos fóruns, wikis e blogs, no ambiente virtual de aprendizagem, ao longo dos quatro anos de curso.

\section{Dados e Análises}

\subsection{Fóruns}

Os fóruns são discussões assíncronas que se desenvolvem a partir de um tema ou uma questão proposta. Em cada turma do curso investigado, foram abertos, desde o primeiro semestre, pelo menos três fóruns online: Fórum de Notícias, Hora do Cafezinho e um fórum temático. Ao longo do curso, outros fóruns foram sendo demandados, ora pelos alunos, ora pela equipe de tutoria. A seguir caracterizaremos a proposta e a utilização de cada um deles:
- Fórum de Notícias: A proposta desse fórum era manter os alunos informados, por meio da publicação, em sua maioria pela equipe de tutoria, de notícias e avisos sobre o curso.

- Hora do Cafezinho: Por ser um espaço aberto para os alunos e tutores conversarem informalmente sobre assuntos diversos, este fórum apresentou maior diversidade de mensagens, desde acordos de encontros, atividades, horários entre os alunos, assuntos da atualidade a textos com reflexões morais e/ou humorísticas e/ou motivadoras e/ou religiosas.

- Fórum Temático: Fórum com atividade para integração dos conteúdos curriculares abordados nos guias impressos do curso, com temas variados. Neste fórum, a proposição de abertura se apoiava em elementos diversos, tais como questões, imagens, vídeos ou textos.

- Fórum Sobre Metodologia de Pesquisa e de Apoio à Construção da Monografia: A partir do terceiro semestre, quando os alunos iniciaram a construção do projeto de pesquisa para a elaboração da monografia, passou-se a abrir, também em cada turma, um fórum para se discutir aspectos metodológicos ou sobre os temas escolhidos para as pesquisas.

- Fórum de Dúvidas: Este fórum teve a proposta de ser um espaço para envio, pelos alunos, de quaisquer dúvidas sobre os conteúdos em estudo ou sobre o próprio curso. Para além do envio de perguntas e respostas, o fórum de dúvidas mostrou-se, muitas vezes, como espaço de conversas sobre os conteúdos estudados nos componentes curriculares, complementando a proposta dos fóruns temáticos. 
- Fórum Sobre o Estágio: Ao longo do curso, as conversas sobre o estágio curricular foram aparecendo nos fóruns, principalmente na Hora do Cafezinho e no Fórum de Dúvidas. A partir do quinto semestre letivo, o fórum sobre estágio foi aberto nas turmas, prevendo uma participação livre, não obrigatória. Os alunos puderam escrever sem estarem necessariamente cumprindo uma tarefa. E percebemos que o espaço, embora não sendo este um dos fóruns com maior número de mensagens, abrigou trocas e desabafos, conversas e reflexões sobre o que os alunos estavam vivenciando.

Propusemo-nos observar, sistematicamente, as interações discursivas nos fóruns, em cada um dos 8 semestres letivos do curso. Inicialmente, realizamos um ensaio dessa análise (MEDEIROS; NASCIMENTO, 2009), observando apenas as turmas de um polo no primeiro semestre. Em seguida, estendemos a análise aos outros fóruns, aos outros polos e aos outros semestres letivos. As mensagens postadas nos fóruns foram categorizadas de acordo com aspectos relacionados à frequência e ao conteúdo das mensagens enviadas por alunos e tutores. Tomamos como parâmetros apenas os aspectos comunicacionais da interação, limitados conforme Nascimento (2007) em: o capital de fala (número de turnos de fala), a finalidade da fala (questão ou resposta) e o padrão interacional (conteúdo da mensagem dentro de uma sequência). A partir dessa organização dos dados, identificamos algumas sequências que se mostraram recorrentes:
QUADRO 1 - Sequências Identificadas na Organização dos Fóruns.

\begin{tabular}{|c|c|}
\hline $\begin{array}{l}\text { Sequên- } \\
\text { cia } 1\end{array}$ & $\begin{array}{l}\text { - Tutor abre o tópico } \\
\text { - Alunos respondem/comentam } \\
\text { - Tutor responde/comenta as mensa- } \\
\text { gens dos alunos individualmente } \\
\text { - Há pouca ou nenhuma troca comuni- } \\
\text { cativa entre as mensagens dos alunos }\end{array}$ \\
\hline $\begin{array}{l}\text { Sequên- } \\
\text { cia } 2\end{array}$ & $\begin{array}{l}\text { - Tutor abre o tópico } \\
\text { - Alunos respondem/comentam } \\
\text { - Não há respostas/comentários de } \\
\text { tutores } \\
\text { - Não há troca comunicativa entre as } \\
\text { mensagens dos alunos }\end{array}$ \\
\hline $\begin{array}{l}\text { Sequên- } \\
\text { cia } 3\end{array}$ & $\begin{array}{l}\text { - Tutor abre o tópico } \\
\text { - Alunos respondem/comentam } \\
\text { - Não há respostas/comentários de } \\
\text { tutores } \\
\text { - Existe troca comunicativa entre as } \\
\text { mensagens dos alunos }\end{array}$ \\
\hline $\begin{array}{l}\text { Sequên- } \\
\text { cia } 4\end{array}$ & $\begin{array}{l}\text { - Tutor abre o tópico } \\
\text { - Alunos respondem/comentam } \\
\text { - Tutor responde/comenta as mensa- } \\
\text { gens de vários alunos em mensagem } \\
\text { única } \\
\text { - Não há troca comunicativa entre as } \\
\text { mensagens dos alunos }\end{array}$ \\
\hline $\begin{array}{l}\text { Sequên- } \\
\text { cia } 5\end{array}$ & $\begin{array}{l}\text { - Aluno abre o tópico } \\
\text { - Não há respostas/comentários de } \\
\text { alunos } \\
\text { - Não há respostas/comentários de } \\
\text { tutores }\end{array}$ \\
\hline $\begin{array}{l}\text { Sequên- } \\
\text { cia } 6\end{array}$ & $\begin{array}{l}\text { - Aluno abre o tópico } \\
\text { - Alunos respondem/comentam } \\
\text { - Existe troca comunicativa entre as } \\
\text { mensagens dos alunos }\end{array}$ \\
\hline
\end{tabular}

FONTE: Elaborado pelas próprias autoras.

A sequência 1 aconteceu nos casos em que o tópico proposto abria espaço para a postagem de dúvidas ou questões acerca de determinado assunto: os alunos postaram suas mensagens e o tutor as respondeu individualmente. A falta de troca comunicativa entre as mensagens dos alunos se justifica pela diversidade de dúvidas, mas pode ser considerada ainda, pela não leitura dos comentários já postados.

As sequências 2 e 3 foram observadas nos casos da postagem de algum aviso ou mensagem de caráter informativo ou motivador, em 
que os alunos responderam, ora apenas dando ciência, ora reforçando ou agradecendo o conteúdo da mensagem postada. Em alguns casos, houve troca comunicativa entre as mensagens dos alunos, em outros não.

A sequência 4 foi observada nos casos em que o tutor propunha um tópico de discussão e os alunos se mostravam preocupados em dialogar e/ou responder ao tutor, não havendo troca comunicativa entre as mensagens dos alunos. Entretanto, ao responder, o tutor, em uma só mensagem, interagia com vários alunos, mostrando, implicitamente, que o diálogo poderia/deveria se estabelecer.

As sequências 5 e 6 apareceram principalmente no fórum Hora do Cafezinho e nos fóruns temáticos, onde foi possível observar muitas aberturas de tópicos sem nenhum comentário (sequência 5) e, em menor número, os tópicos com comentários e respectiva interatividade, mais entre alunos do que entre alunos e tutores (sequência 6). Essas sequências aproximam-se da sequência 4 , no caso do fórum temático, onde percebemos uma preocupação dos alunos em postar um novo tópico em um fórum que os convidava a discutir uma temática relacionada ao conteúdo do curso, mas sem a percepção de que seria interessante também dialogar com as mensagens já postadas pelos colegas.

Ao nos propormos examinar tais sequências de interação sob os princípios da análise da conversação, remetemo-nos, inicialmente, às condições básicas, como a existência do assunto sobre o que conversar, ou seja, a interação centrada. Vimos que os fóruns possuem temáticas bem definidas e um texto introdutório que abre a comunicação, orientando-a. Nesse sentido, destacamos a importância de haver fóruns com finalidades distintas, evitando-se que mensagens não relacionadas à discussão proposta fossem enviadas, ou seja, a perda do foco, da interação centrada. A existência de mais de um interlocutor e pelo menos uma troca de turno também são condições observadas, com exceção apenas das situações em que um aluno posta um tópico sem interagir explicitamente com os comentários já postados e/ou sem que nenhum outro comentário seja postado em resposta (sequência 5). Essas mesmas situações devem ser consideradas também ao nos referirmos ao engajamento dos participantes, amplamente presente nos momentos em que há interação ou mesmo a preocupação em responder a um tópico aberto pelo tutor (sequências 3 e 6). Nos casos em que as mensagens postadas não dialogam entre si (sequências 1, 2 e 4), não podemos dizer que haja o engajamento, já que não há uma troca comunicativa, isto é, as pessoas falam alternadamente, mas não se falam (KERBRAT-ORECCHIONI, 2006).

Entretanto, não podemos inferir que nos casos em que não houve a postagem de comentários / respostas ou que não tenha acontecido a troca comunicativa, não tenha acontecido a produção de sentidos. Primeiro porque há sujeitos que não registraram sua presença com a escrita, mas leram as mensagens postadas, conforme afirma a aluna Sandra:

O contato com o moodle foi importantíssimo, aprendi muitas coisas, apesar de não participar o quanto deveria nos fóruns, aprendi muito com eles, lendo as respostas dos colegas, e com a intervenção do tutor sanando dúvidas (Resposta à questão 10 do questionário 2, 12/10/2011).

Segundo, porque mesmo que a mensagem postada pareça responder apenas à tarefa solicitada pelo tutor, ela busca interação, porque toda enunciação, mesmo que monológica, responde aos enunciados que a precederam e dirige-se a um interlocutor que interferiu nessa 
construção (BAKHTIN, 2006). Nesse ponto, a análise conversacional mostra-se limitada para a compreensão da escrita no ambiente virtual de aprendizagem, embora alguns de seus elementos tenham se mostrado convenientes ao nosso estudo.

Estender essa análise aos fóruns dos oito semestres possibilitou-nos uma visão longitudinal, de onde pudemos perceber alterações na organização das discussões, assim como variações nas práticas discursivas. A Figura 2 sintetiza duas formas de organização das sequências conversacionais que se constituíram em diferentes momentos ao longo do curso, influenciadas pela proposta de abertura e pelas condições de interação que foram se estabelecendo em cada turma.

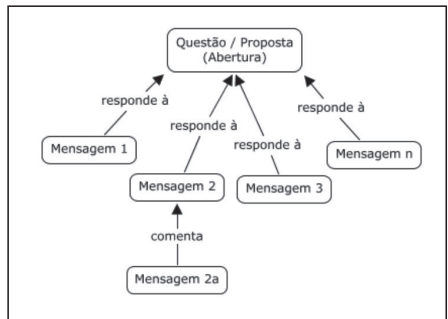

A) Tipo 1

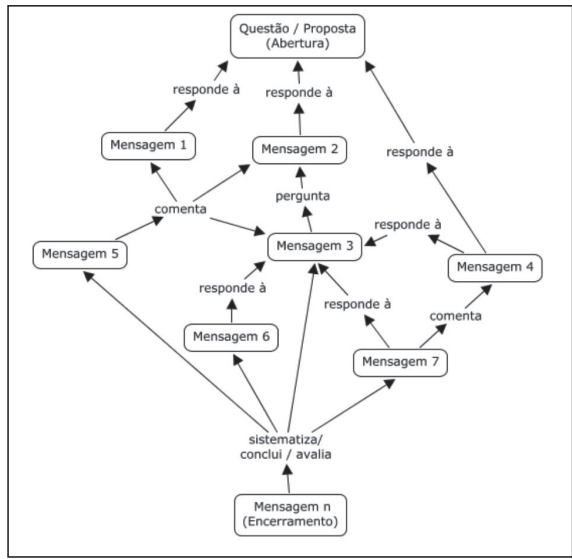

B) Tipo 2

FIGURA 2 - Organização das Sequências (tipo 1 e 2). FONTE: Elaborado pelas próprias autoras.
Na Figura 2 temos a sequência A característica de: (a) situações em que a mensagem de abertura possuía um caráter mais informativo, em que os alunos apenas respondiam dando ciência; (b) situações em que os fóruns foram abertos dando a possibilidade aos alunos de abrirem novos tópicos, fazendo com que muitos tópicos fossem criados, mas poucos deles fossem comentados pelas mensagens seguintes, (c) situações em que o tutor abria um tópico com uma questão para discussão, mas os alunos, ainda não tendo se apropriado do gênero demandado por um fórum de discussão, apenas respondiam ao tutor, como se estivessem cumprindo uma tarefa e sendo avaliados por essa resposta. Nessa sequência, foram raros os casos em que novas mensagens interagiam com as mensagens já postadas.

$E$, também, na Figura 2 temos uma sequência $\mathrm{B}$ mais complexa, que nos mostra a forma como a interação foi se estabelecendo ao longo das mensagens postadas, com respostas, $\mathrm{CO}^{-}$ mentários e novas questões sendo inseridas. Nessa sequência, a centralidade do papel do tutor e da própria tarefa dá lugar ao diálogo, não raro, marcado por uma escrita mais espontânea e menos formal.

\subsection{Wikis}

Os wikis são páginas que permitem a construção online de textos coletivos, nos quais, via de regra, todos os participantes podem fazer alterações, colaborando na construção de um mesmo material. Além de democratizar a edição, outro princípio do wiki é democratizar a publicação, ou seja, todos podem editar e, ao salvar as alterações que realizaram, podem publicá-las imediatamente, sem que essa função seja privilégio de um grupo de revisores. 
No curso em estudo, atividades com wikis aconteceram em dois momentos. No segundo semestre letivo, foi proposta às turmas a construção online de um texto coletivo acerca do tema o texto e o leitor, tema este relacionado aos conteúdos estudados e já discutido em um fórum temático naquele semestre. No terceiro semestre do curso, em outra atividade também propondo a construção online de um texto coletivo, cada turma foi organizada em grupos de quatro ou cinco pessoas e cada grupo construiu um texto. Realizamos observações semanais aleatórias ao longo do período em que as atividades estavam em andamento e observações sistemáticas ao final de cada período letivo, quando as atividades eram encerradas. Na leitura flutuante (BARDIN, 1977), coletávamos informações processuais importantes para estruturar a observação e coleta sistematizadas ao final da atividade. Nos textos dos wikis, inicialmente nossas unidades de análise foram as postagens individuais e, em cada uma delas, consideramos os seguintes itens: a) a ação realizada, se inseriu, excluiu, alterou, corrigiu ou revisou textos; b) o objeto da ação, se espaços, palavras, frases, parágrafos ou todo o texto; c) a quantidade de caracteres envolvidos na ação; d) a posição em que ação foi realizada, se no início, ao final ou em outro ponto, diferente desses. Pudemos perceber que os alunos tiveram dificuldades em lidar com a edição coletiva do texto e, nesse sentido, elencamos alguns aspectos que julgamos merecer maior atenção:

- Iniciado o texto, as contribuições foram sendo inseridas ao final. Foram raras as alterações na parte inicial e inexistentes as inserções de textos antes do primeiro parágrafo. Assim, quem inicia, acaba dando o tom.
- A forma de contribuição mais presente foi a inserção de textos $(75,4 \%)$, ao final $(66,7 \%)$, como novo parágrafo $(52,6 \%)$ ou adicionando frases ao final do último parágrafo $(19,3 \%)$.

- As pessoas vão dando continuidade ao texto, sem tocar no texto que o colega já escreveu. Buscam conectar com o que já foi escrito, normalmente concordando e/ou complementando o raciocínio. Com menor frequência são propostos raciocínios em outras direções.

- Foram raras as ações de exclusão, alteração, correção ou revisão dos textos escritos pelos colegas, mesmo em casos em que erros de digitação ou ortografia eram visíveis. Dentre os $14 \%$ que realizaram alterações, $8,8 \%$ o fizeram nas partes dos textos inseridos por eles mesmos.

A dificuldade dos alunos (e também dos tutores) em lidar com o texto coletivo no ambiente virtual de aprendizagem nos coloca diante de algumas questões acerca do gênero textual que é proposto neste espaço de escrita online. Que outras práticas de leitura e escrita seriam semelhantes a tal produção? Em que outros momentos os sujeitos experimentaram argumentar contra o que já estava posto na escrita do colega? Não obstante algumas formas de debates orais ou de elaboração presencial de texto por mais de uma pessoa, essa forma de exercício da autoria proposta pelo wiki não encontra muitos precedentes em outros meios. Daí podemos melhor compreender os motivos que inibem os alunos de interferir no texto já postado, de discordar de ideias, mudar a direção da argumentação, corrigir erros de digitação e/ou de ortografia. 
As condições de produção nos possibilitam contextualizar essa escrita também no intuito de compreender as ações dos sujeitos dentro do wiki. Trata-se de uma tarefa proposta e que está sendo avaliada dentro do curso de graduação. Mexer no texto do outro pode significar interferir na avaliação da tarefa do outro. A espontaneidade presente na escrita nos fóruns é quase ausente no texto coletivo no wiki, que se reduz quase totalmente a uma escrita para o cumprimento de uma tarefa. Somos levados a pensar que a construção do texto no wiki não teve muito sentido para o sujeito para além daquele momento, visto como mais uma tarefa. Outro ponto importante a se considerar é que o próprio wiki não contempla um espaço de conversa / discussão que possibilite ao sujeito sugerir ou questionar o colega, expondo sua argumentação, antes de interferir diretamente em seu texto. Pode ser que a construção de um texto coletivo no wiki contando com um fórum de apoio à construção desse texto fosse mais produtivo.

\subsection{Blogs}

Os blogs destinam-se à publicação de textos individuais, normalmente com espaço para inserção de comentários dos leitores. No quarto semestre do curso foi proposto aos alunos que publicassem no espaço do blog informações sobre si mesmos e sobre seus temas de pesquisa. Tal atividade teve continuidade nos semestres seguintes, com o objetivo de tornar pública dentro de cada turma a temática trabaIhada em cada monografia.

Também nos blogs realizamos observações flutuantes ao longo do processo e, finalizado o semestre letivo, procedemos à coleta sistematizada dos dados, considerando os seguintes itens: a) ter conteúdo publicado; b) se esse conteúdo consiste em relatos para o blog ou se são cópias de outros textos; c) os elementos que compõem as postagens - textos, imagens, fotografias, links e outros; d) se atingiram o objetivo proposto e, para tanto, estabelecemos como critério mínimo estar explicitado no blog o tema da pesquisa de monografia. Organizados em arquivos de texto, por polo, os blogs somaram cerca de 800 páginas, sendo que, naquele momento, 241 (68,1 \%) alunos já haviam publicado textos em seus blogs e 113 alunos (31,9 \%) ainda tinham os blogs vazios.

Durante as observações, percebemos que o blog se prestou a um importante papel de registro: para o memorial da trajetória escolar vivida antes do ingresso no curso de graduação; para o relato das experiências vividas nos estágios curriculares em turmas da educação infantil e do ensino fundamental; para o percurso de construção do projeto de pesquisa; para a realização da pesquisa e elaboração da monografia. Destacamos a seguir as tendências observadas e que consideramos importante destacar em nossas análises sobre como esse espaço foi utilizado pelos alunos:

Um espaço para se dar a conhecer pelo outro - nesse grupo encontramos tanto aqueles que publicaram seus memoriais ${ }^{3}$ na íntegra, quanto os que selecionaram trechos do memorial para publicar no blog e ainda os que tomaram o blog como uma extensão do memorial e continuaram a registrar ali a sua trajetória de vida pessoal, familiar, acadêmica e profissional.

O blog como diário de bordo - foi o que percebemos nos blogs que traziam relatos sobre: a experiência de escrita do memorial, com reflexões sobre o significado de relembrar o pas-

\footnotetext{
${ }^{3}$ O Memorial foi escrito pelos alunos durante os três primeiros semestres letivos, como forma de resgatar e registrar a trajetória de vida e subsidiar as escolhas e a escrita da monografia.
} 
sado e registrá-lo; a definição do tema de pesquisa, explicitando as motivações e as dúvidas, as idas e vindas nas mudanças de temas; o estágio curricular, com narrativas de episódios vividos ou presenciados nas salas de aula, nas escolas; o processo de pesquisa, incluindo o estudo empírico e o referencial teórico, as dificuldades, os materiais encontrados. Em todos esses casos, os registros são textos pequenos, anotações que foram sendo feitas dia após dia.

O blog como exposição da pesquisa - e aí vemos os blogs que apresentam: textos copiados na íntegra, fichamentos de textos lidos, imagens, links para artigos ou notícias, todos relacionados ao tema que o sujeito escolheu pesquisar.

Para além do registro, os blogs se mostraram como um espaço único de escrita autoral, de registro da trajetória de cada sujeito, de publicação, de socialização - do autor e de sua produção. Observamos que, embora a orientação que os alunos receberam tenham sido as mesmas em todas as turmas, o espaço do blog não foi usado homogeneamente: tivemos blogs com 4 ou 5 linhas de texto, tivemos blogs com alguns parágrafos e tivemos blogs com 30 páginas; havia blogs com textos somente e havia blogs com muitas imagens e links; havia textos sobre o curso, o memorial, o estágio, a monografia e havia orações, mensagens de autoajuda, depoimentos, fotos das férias com a família. Esse aspecto heterogêneo, demonstrando certa dispersão, também nos levou a perceber que os sujeitos estavam tomando o espaço mais como seu, ampliando a sua utilização, de certo modo transgredindo a proposta inicial, o que não se observou nos fóruns e nos wikis. Por outro lado, explicitou-se também a não compreensão sobre o gênero textual característico do blog, já que muitos alunos copiaram e colaram em seus blogs, na íntegra, seus memoriais, projetos de pesquisa e até mesmo relatórios de estágio. A escrita no blog revelou-se, assim, ora com a estrutura formal característica de outros gêneros (fichamentos, projetos de pesquisa, etc.), ora com total espontaneidade e informalidade, quando as pessoas se expuseram mais e dialogaram mais com os colegas.

\section{Conclusões}

Neste estudo, voltamos o nosso olhar para os espaços de autoria em um ambiente virtual de aprendizagem, buscando compreender as relações que os sujeitos constroem entre si e com o próprio ambiente por meio da escrita online. Pudemos identificar e descrever algumas das formas de organização das interações nos fóruns, verificando as principais características estruturais e organizacionais (sequências, organizadores globais, marcadores conversacionais verbais, coerência conversacional e organização de tópicos), chegando a propor algumas interpretações e considerações interessantes ao ensino a distância. Ao detalharmos e analisarmos os itens relacionados ao conteúdo das mensagens postadas e à existência ou não de trocas comunicativas, estávamos explicitando, de forma sistematizada, aspectos inerentes ao exercício da autoria e ao funcionamento de um fórum online em um ambiente virtual de aprendizagem. Examinamos também os textos produzidos nos wikis e blogs, realizando inicialmente uma análise exploratória do conteúdo, de onde destacamos nossas inferências e algumas interpretações possíveis.

Observando a escrita dos sujeitos nesses diferentes espaços, pudemos perceber as tendências de um processo de autoria, seja 
quando estavam narrando suas experiências no estágio, ou respondendo às solicitações dos tutores, respondendo dúvidas dos colegas ou mesmo respondendo a uma tarefa. Vimos situações que colocaram o sujeito numa atitude responsiva ativa e não somente de leitor de materiais postados por uma equipe de tutoria.

Não temos propriedade para inferir sobre as práticas de escrita em documentos de texto que são posteriormente enviados/postados no ambiente virtual, já que tal atividade pode ser, e muitas vezes o é, manuscrita em papel e depois digitada por outra pessoa. Diferentemente, na escrita online, mesmo que inicialmente também seja manuscrita e posteriormente digitada e requeira ao auxílio de outra pessoa, com o tempo, o sujeito se vê estimulado a fazer por si mesmo, a digitar e enviar suas mensagens.

Para caracterizar e sistematizar nossas análises acerca da escrita no ambiente virtual de aprendizagem, apresentamos na Figura 3 um diagrama sobre onde, para quem, como, por quê e para quê os sujeitos desta pesquisa escreviam:

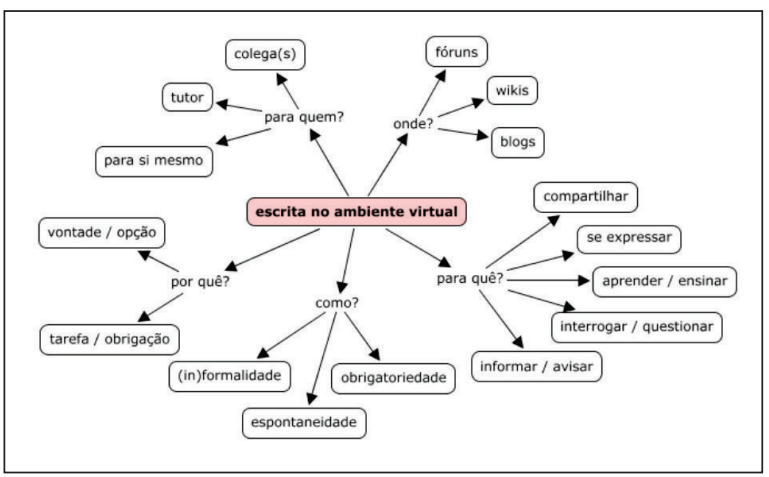

FIGURA 3 - A Escrita no Ambiente Virtual de Aprendizagem.

FONTE: Elaborado pelas próprias autoras.

Ao buscar-se compreender por que o texto é escrito, para quem é escrito, como é es- crito e o que mais se puder perceber a partir dessa escrita, reconhece-se o processo educativo nesse ambiente como linguisticamente e socialmente constituído. Compreendemos o exercício da autoria como a escrita que possibilita ao sujeito expressar-se, externalizar seu pensamento, publicar sua fala, seu texto, ainda que o incorporando a um espaço e a um texto coletivos. Assim como Bakhtin (2006), ressaltamos a natureza social e histórica dessa produção de enunciados que nos propusemos investigar. Consideramos que compreendendo as sequências nas interações nos fóruns e os textos publicados nos blogs e wikis como enunciados produzidos por sujeitos engajados em um contexto específico, um ambiente virtual de aprendizagem, pudemos melhor interpretar as relações ali estabelecidas por meio da escrita. A filosofia da linguagem permitiu-nos perceber essa dimensão da interação verbal que ali se constituía, fortemente marcada pela realidade imediata e pelo meio social mais amplo. Esse olhar nos possibilita ainda perceber a escrita dos alunos no ambiente virtual não apenas sob os aspectos linguísticos, mas principalmente sob os aspectos socioculturais.

Na educação a distância, em que o leitor (aluno ou tutor) encontra-se distante temporalmente e geograficamente de quem produziu ou escreveu cada tela, compreender essa construção de significados pelo sujeito muito pode contribuir no planejamento e na organização dos ambientes virtuais de aprendizagem. E, principalmente, a análise da escrita dos alunos sob tais perspectivas muito dão a conhecer sobre esses sujeitos e o seu processo de aprendizagem. Ousamos sugerir que o que esta pesquisa conclui no contexto da educação a distância também tem suas aplicações no ensino presencial, a partir do uso de tais tecnologias como mais uma estratégia peda- 
gógica potencializadora do processo de ensino e aprendizagem. Contextos de autoria como os que aqui analisamos (fóruns, wikis e blogs) têm sido utilizados por muitos professores na educação básica e no ensino superior presencial. Cabe reconhecermos e problematizarmos as contribuições que a escrita autoral nesses espaços traz para os processos de aprendizagem vivenciados pelos sujeitos.

É importante compreendermos que o ambiente virtual de aprendizagem é um espaço que viabiliza a distribuição da informação e a comunicação entre tutores e alunos, entre alu- nos e alunos e entre tutores e tutores. Uma comunicação de mão dupla, da qual todos devem poder participar postando suas mensagens, tarefas e materiais de estudo. Desse modo, para favorecer a atitude ativa responsiva do sujeito, é importante que esse ambiente se configure como um contexto de autoria, com espaços abertos à escrita do aluno. Que não seja um ambiente usado apenas com fins informativos (avisos, textos etc.), mas também como espaço de mediação, de diálogo, de discussão sobre os temas curriculares e de expressão dos sujeitos.

\section{Referências}

AMORIM, J.A. Educação em Engenharia: o desenvolvimento de um aplicativo de autoria para a elaboração de mapas conceituais e hipertextos. 2005. Dissertação (Mestrado em Engenharia Elétrica) Universidade Estadual de Campinas, 2005, Campinas, BR-SP.

AXT, M. Linguagem e Telemática: tecnologias para inventar: construir conhecimento. Revista Educação Subjetividade \& Poder, Ijuí, v. 5, n. 5, p. 20-30, 1998.

AXT, M. Comunidades Virtuais de Aprendizagem. Informática na Educação: teoria \& prática, Porto Alegre, v. 7, n. 1, p. 111-116, jan./jun. 2004.

AXT, M. Comunidades Virtuais de Aprendizagem e Interação Dialógica: do corpo, do rosto e do olhar. [São Leopoldo, 2006]. Palestra proferida no evento O Rosto e o Olhar, na UNISINOS, em 17/08/2006, São Leopoldo, BR-RS.

AXT, M.; ELIAS, C.R. Autoria Coletiva, Ambientes Virtuais e Formação: quando a aprendizagem reverbera o acontecimento. In: MARASCHIN, C.; FREITAS, L.B.; CARVALHO, D.C. (Org.). Psicologia e Educação: multiversos sentidos, olhares e experiências. Porto Alegre: UFRGS, 2003. V. 1, p. 259-277.

AXT, M. et al. Interação Dialógica: uma proposta teórico-metodológica em ambientes virtuais de aprendizagem. RENOTE: Revista Novas Tecnologias na Educação, Porto Alegre, v. 4, n. 1, jul. 2006. Disponível em: <seer.ufrgs.br/renote/article/download/14041/7929> Acesso em: 30 abr. 2011. 
BAKHTIN, M. Os Gêneros do Discurso. In: BAKHTIN, M. Estética da Criação Verbal. 2. ed. São Paulo: Martins Fontes, 1997. P. 277-326. (1a edição, 1992; edição original em russo, 1979).

BAKHTIN, M. Marxismo e Filosofia da Linguagem. 12. ed. São Paulo: Hucitec, 2006.

BARDIN, L. Análise de Conteúdo. Lisboa: Ed. 70, 1977.

BEICHNER, R.J. Multimedia editing to promote science learning. Journal of Educational Multimedia and Hypermedia, Raleigh, n. 3, p. 55-70, 1994.

BEZERRA, E.S. A Criança e a Relação com a Escrita: o processo de autoria nos textos infantis. 2008. Dissertação (Mestrado em Linguística e Ensino) - Universidade Federal da Paraíba, 2008, João Pessoa, BR-PB.

CHARTIER, R. A Aventura do Livro: do leitor ao navegador. São Paulo: Ed. UNESP; Imprensa Oficial do Estado, 1999.

FRANCELINO, P.F. A Autoria no Gênero Discursivo Aula: uma abordagem enunciativa. 2007. Tese (Doutorado em Letras) - Universidade Federal de Pernambuco, 2007, Recife, BR-PE.

FREITAS, M.T.A.; COSTA, S.R. (Org.). Leitura e Escrita de Adolescentes na Internet e na Escola. Belo Horizonte: Autêntica, 2005.

FREITAS, M.T.A.; PEREIRA, M.L. Práticas de Escrita e Autoria: a utilização dos blogs literários nas aulas de língua portuguesa. In: ENCONTRO NACIONAL SOBRE HIPERTEXTO, 3., 2009, Belo Horizonte. Anais. Belo Horizonte, 2009. P. 105.

KERBRAT-ORECCHIONI, C. Análise da Conversação: princípios e métodos. Tradução: Carlos Piovezani Filho. São Paulo: Parábola Ed., 2006.

KLIS, Henk-Jan van der. Weblog. Balkbrug, NL: [s.n.], 2008. Disponível em: <http://www.henkjanvanderklis.nl/weblog/labels/web\%204.0.html> Acesso em: 30 abr. 2011.

LIMA, C.S. Aspectos Discursivos da Constituição da Autoria em Resenhas Acadêmicas. 2008. Dissertação (Mestrado em Linguística) - Universidade Federal de Uberlândia, 2008, Uberlândia, BR-SP.

LIMA, M.D.A. Ambiente de Autoria de Cursos Hipermídia Estendidos. 2002. Dissertação (Mestrado em Ciência) - Instituto Tecnológico de Aeronáutica, 2002, São José dos Campos, BR-SP. 
MARCUSCHI, L.A. Análise da Conversação. 5. ed. São Paulo: Ed. Ática, 2006.

MEDEIROS, Z. Letramento Digital em Contextos de Autoria na Internet. 2011. Tese (Doutorado em Educação) - Universidade Federal de Minas Gerais, 2011, Belo Horizonte, BR-MG.

MEDEIROS, Z.; NASCIMENTO, S.S. Interações Discursivas em um Fórum Online. In: ENCONTRO DE PESQUISA EM EDUCAÇÃO DA REGIÃO SUDESTE (ANPEDINHA), 9., 2009, São Carlos, BR-SP. Pesquisa em Educação no Brasil: balanço do século XX e desafios para o século XXI. São Carlos: Cubo Multimídia, 2009. V. 1, p. 142-143.

NASCIMENTO, S.S. A Linguagem e a Investigação em Educação Científica: uma breve apresentação. In: NARDI, R. (Org.). A Pesquisa em Ensino de Ciências no Brasil: alguns recortes. Bauru: ABRAPEC, 2007. P. 131-142.

PRIMO, A.F.T.; RECUERO, R.C. Hipertexto Cooperativo: uma análise da escrita coletiva a partir dos Blogs e da Wikipédia. Revista FAMECOS, Porto Alegre, n. 22, p. 54-65, dez. 2003.

SAADE, D.C.M. Relações em Linguagens de Autoria Hipermídia: aumentando reuso e expressividade. 2003. Tese (Doutorado em Informática) - Pontifícia Universidade Católica do Rio de Janeiro, 2003, Rio de Janeiro, BR-RJ.

Submetido para avaliação em 02 de janeiro de 2015.

Aprovado para publicação em 18 de março de 2015.

Zulmira Medeiros - Universidade Federal de Minas Gerais, Belo Horizonte, BR-MG. E-mail: zulmiram@ufmg.br Silvania Sousa Nascimento - Universidade Federal de Minas Gerais, Belo Horizonte, BR-MG. E-mail: silnascimento@ ufmg.br 